UC-20d

Issued: August 1985

LA- -10475-MS

DE86 004371

\title{
Multichannel Analog Temperature Sensing System
}

\author{
Rita Gribble
}

\section{DISCLAIMER}

This report was prepared as an account of work sponsored by an agency of the United States Government. Neither the United Siates Government nor any agency thereof, nor any of their employees, makes any warranty, express or implied, or assumes any legal liaoility or responsibility for the accuracy, completeness, or usefulness of ary information, apparatus, product, or process disclosed, or represents that its use would not infringe privately owned rights. Reference herein to any specific commercial product, process, or service by trade name, trademark, mantfacturer, or otherwise does not necessarily constitute or imply its endorsement, recommendation, or favoring by the United States Government or any agency thereof. The views and opinions of autkors expressed herein do not necessarily state or reflect those of the United States Government or any agency thereof.
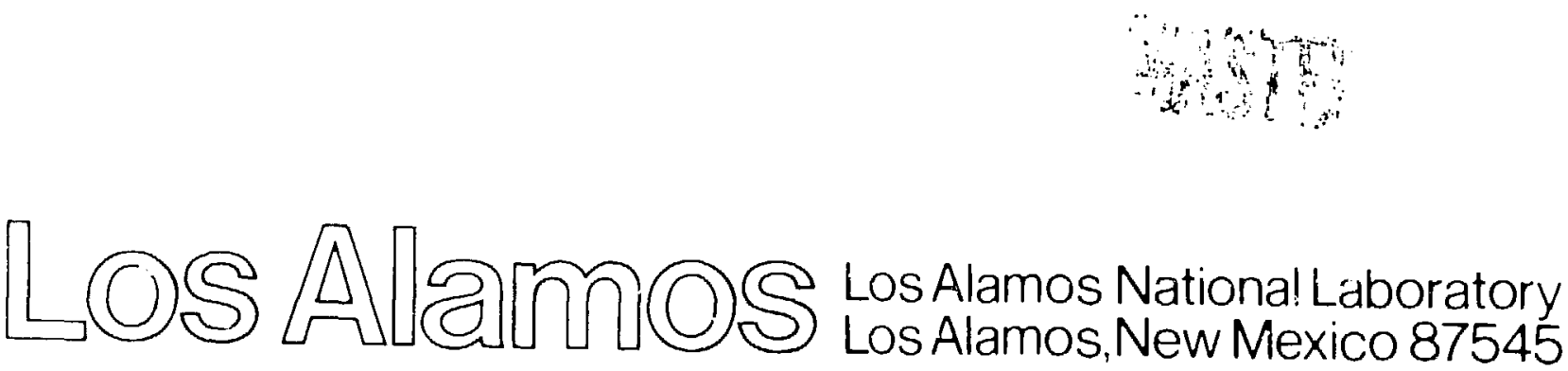
MULTICHANNEL ANALOG TEMPERATURE SENSING SYSTEM

by

Rita Gribble

\begin{abstract}
A multichannel system that protects the numerous and costly water-cooled magnet coils on the translation section of the FRX-C/T magnetic fusion experiment is described. The system comprises a thermistor for each coil, a constant current circuit for each thermistor, and a multichannel analog-to-digital converter interfaced to the computer.
\end{abstract}

\title{
I. INTRODUCTION
}

The magnetic fusion experiment $\mathrm{FRX}-\mathrm{C} / \mathrm{T}$ has 116 water-cooled magnet coils on the translation section. The coils are constructed in sets of two, forming a single pancake. The replacement cost is approximately $\$ 10 \mathrm{~K}$ per pancaice; therefore, it has been necessary to assure that the temperature of any coil does not exceed a safe limit. Two redundant sensing and protection systems have been installed, a digital and an analog system. The digital system has four thermostats (preset thermal switches) per pancake, two pairs of switches per coil connected in series. One pair of switches opens at $66^{\circ} \mathrm{C}$ and provides a warning to the operator of the experiment. The other pair opens at $80^{\circ} \mathrm{C}$, and the computer automatically issues an abort command causing the power to be reduced to a safe level on the coils. The analog system uses thermistors that can provide an instantaneous temperature reading for each coll. It is this system that is the subject of this report. The mul.tichannel thermistor system consists of a thermistor for each coil, a constant current circuit for each thermistor, and a multichannel CAMAC $A$ to $D$ converter that is interfaced to the computer.

\section{SYSTEM DESCRIPTION}

The analog temperature sensing system for the $F R X-C / T$ dc coils is a 128 channel thermistor monitor (see Fig.1). The resistance of the thermistor varies with changing temperature, decreasing as the temperature increases. By applying a constant surrent source to the thermistor and measuring the voltage across the thermistor, quantitative temperature changes can be detected. Quad op anps (type LM224 that cost $\$ 1.19$ each) provide the constant current sources 


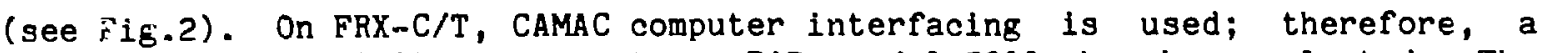
CAMAC analog-to-digital converter, BiRa model 5302, has been selected. The model 5302 supplies 64 channels of analog-to-digital conversion in a scanning mode, for a cost of approximately $\$ 25$ per channel. To make the system as compact as possible the circuitry for the constant current sources was paskaged in a four-wide CAMAC module that is mounted in and receives its power from the same CAMAC crate as the model 5302. This module contains 16 quad op amps and associated electronics for 64 thermistor channels. This number of channels has been selected to be directly compatible with the 5302 module.

The output from the constant current source is connected directly to an input of the model 5302 and in paraliel across the thermistor. Between the current source and the thermistor is a signal conditioning board with filters consisting of series resistance and parallel capacitance (see Fig.2). The filter is provided to protect the electronics from the harsh electromagnetic environment present during the high-voltage plaswa discharges of the FRX-C/T device. In the presence of the violent electromagnetic fields created by energizing the theta pinch coils, the cables connected to the thermistors have picked up transients damaging the electronics in spite of exhaustive attempts to shield the system. The thermistors are connected using shielded, twisted pair cable whose shield is connected to ground at the electronics end but is open on the thermistor end.

The thermistors (G.E. type D103 that cost $\$ 0.89$ each) are epoxied onto the copper connections of the de colls. Care must be taken to insulate the thermistors electrically from the colls while malntaining maximum thermal conduction. The thermal conduction is not severely degraded if a 0.005-in.-thick plece of Kaptan is epoxied between the thermistor and the coil. This will insure electrical insulation of the thermistor fron the coil. The voltage across the thermistor and present at the input to the $A$ to $D$ converter is inversely proportional to the temperature of the thermistor. A careful calibration of voltage vs temperature gives a curve from which the software can extrapolate a temperature (gee Fig.3). The sensitive temperature range of this system is from $15^{\circ} \mathrm{C}$ to $120^{\circ} \mathrm{C}$, which correspondes to a maximum of $9.6 \mathrm{~V}$ and a minimum of $1.2 \mathrm{~V}$ at $120^{\circ} \mathrm{C}$. In a nonhostile electromagnetic environment, the filter circuiv'y can be eliminated with its inherent voltage drop across the resistance thus extending the temperature range of the system. The design is such that if there is a fallure in the thermistor system, the symptoms are obvious. Two likely failure modes can occur. One mode is a short circuit, which will signify an extremely high temperature. This will cause the computer to j.ssue an abort and notify the operator immediately of the problem. In the second mode, the voltage remains at the maximum value, but at normal room temperature (approximately $18^{\circ} \mathrm{C}$ or above), the signal voltage should have besun to drop; therefore, by monitoring the voltages the presence of a problem also is apparent.

The control system computer for the FRX-C/T experiment, a Prime 300 , constantly monitors the thermistor voltages on a time avallable basis. If the time between thermistor readings exceeds two seconds, the operator is notified. This happens only when the demands on the computer are extremely heavy and only rarely occurs. When the voltages are read, the computer looks for two values, 3.0 volts and 2.3 volts, that signify temperatures of $65^{\circ} \mathrm{C}$ and $80^{\circ} \mathrm{C}$. If a reading of 2.4 to 3.0 volts is found, the operator is given a warning that the normal safe temperature has been exceeded. If a reading of 2.3 volts or less is found, the shot will be aborted, which will reduce the power in the colls. 
III. CONCLUSION

A constant current thermistor system has been designed, built and calibrated. It provides a compact means of monitoring many thermal channels. With only the de coils operating, the system functions reliably.

Acknowledgments

Many thanks go to Margaret Harper and Brodie Anderson for their work in assembling the parts for this system, to Phil Klingner for the CAMAC installation and software and to Don Ref for his advice and encouragement.

Reference

1. D.J. Rej, "Design and Construction Details of the FRX-C/T Device: A Compact Toroid Plasma Translation Experiment", Los Alamos National Laboratory Report, LA-10108-MS, August 1984.

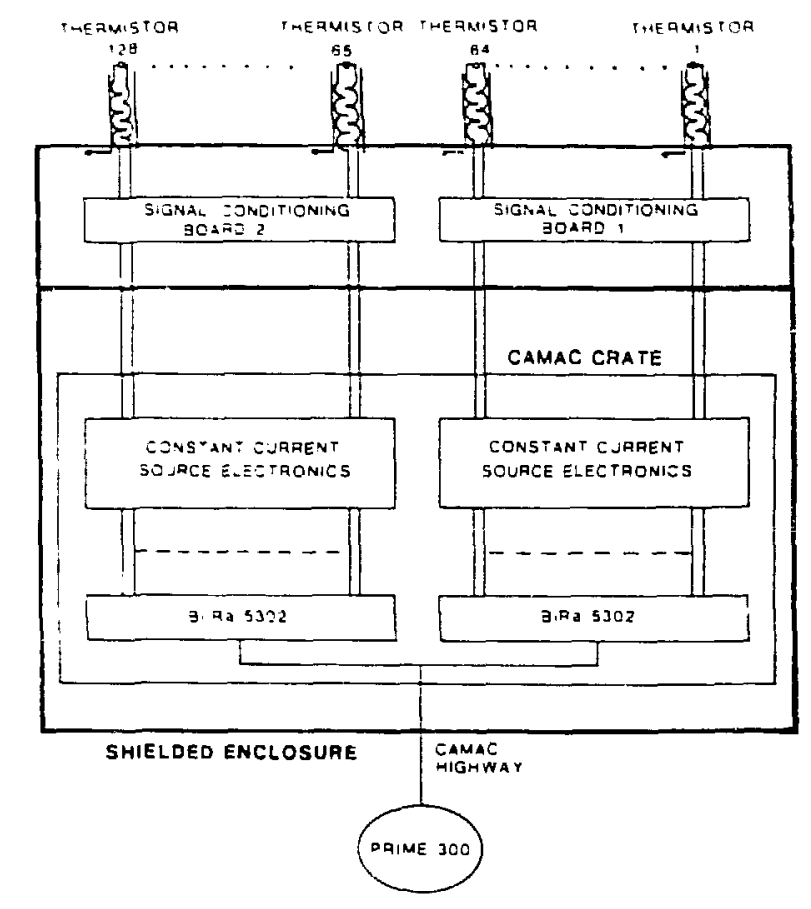

Fig.1. Block diagram of the FRX-C/T multichannel temperature sensing system. 


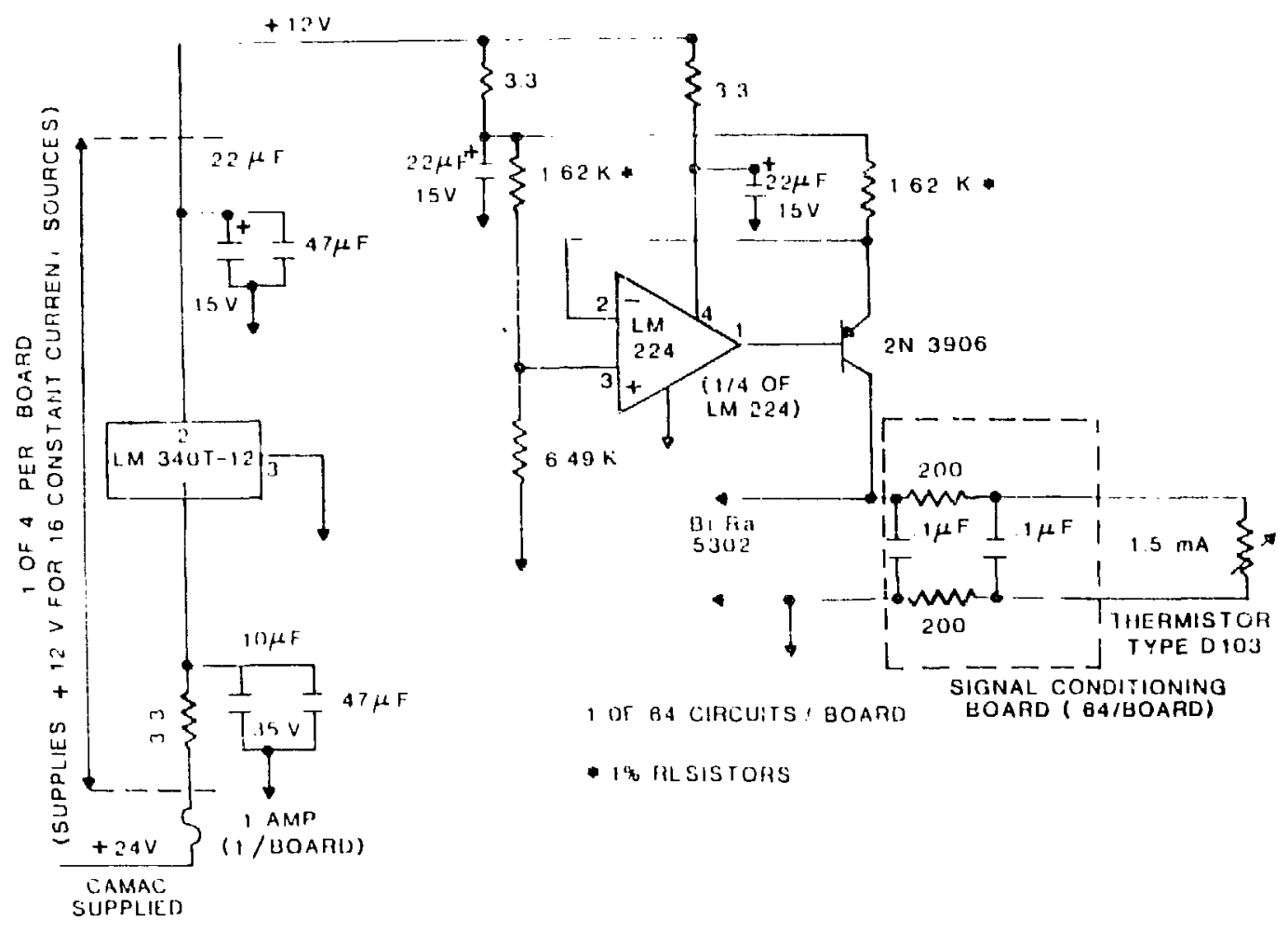

Fig.2. Schematic drawing of the constant current thermistor circuit.

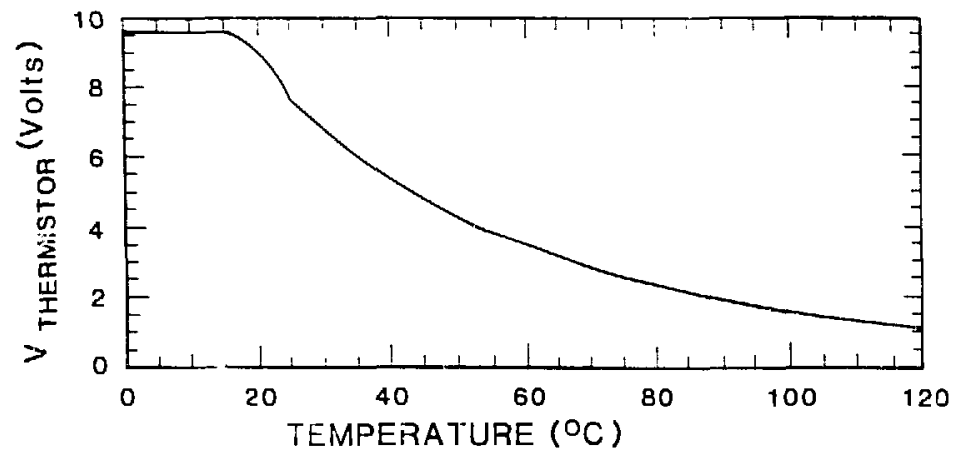

Fig.3. Typical calibration of thermistor voltage against temperature. 